\title{
E-commerce Agricultural Product Marketing and Rental Vehicle
}

\author{
Shreyas P. Deshmukh ${ }^{1}$, Sufiyan R. Tamboli ${ }^{1}$, Pankaj S. Jadhav ${ }^{1}$, Snehal Barawkar ${ }^{2}$ \\ ${ }^{1}$ Department of Computer Engineering, Shree Ramchandra College of Engineering, Pune, Maharashtra, India \\ ${ }^{2}$ Assistant Professor, Department of Computer Engineering, Shree Ramchandra College of Engineering, Pune, \\ Maharashtra, India
}

\begin{abstract}
The motive of the work is to give fair prices to the farmers for their goods. The gap between the farmer and the customer should be removed and the middleman should not interrupt in the farmer and the customer. The sell and buy of the goods from the farmer to the customer should be done with ease. The mahila udyog should grow widely and the mahila groups should gain great profit for their work and their products should be sold in more areas and the small business should widely grow. The exchange of the farming tools and the vehicles should be easy, and more option may be there for the farmers to get the equipment's on proper time and in proper manner. The farmers usually also face a lot of problems in hiring the labours on time which lead to large damage in the crop. The app provides the facility to farmer and the customer to sell their product at fair price and in better manner and to get good product respectively. It also gives farmers and the labours to form groups and hire the available labours and save the crop from damages. As well as the exchange of farming equipment's will be on time for preparation of the farm and in the better manner rather than asking or requesting for the groups.
\end{abstract}

Keywords : Android App, Farmers, Consumer, Farming Vehicles, Farming Tools.

\section{INTRODUCTION}

Farmers are the most important people bringing food in the market. The farmers use older methods to exchange the goods. And mostly sell the goods to the retailers in the village from which they don't earn a good profit.

The farmers are not well connected with the trending technology but most of the framers are for sure well known with the Android technology. So, we are building an android app to make their life easy.
Most of the Mahila in the village come together and form groups and put on their small business but the marketing strategies for there business are limited to the village region and have no opportunities to expand their business widely.

The app is developed to remove the gap between the farmers and the customers. The app provides the service direct connect the farmer and the customer. The farmer can directly sell the goods to the customers without the interference of the middleman in between. And the payment will be received by the farmer directly. 
The second model of our app is the exchange of the farming tools and the farming vehicles required for the preparing the farm. The farmers use old methods for the exchange of tools and the vehicles. The farmers pay for the vehicles and the tools as well but face a lot of problems in getting the equipment's on time which lead to late cultivation of seeds. The small farmers must borrow the equipment's from the wealthy farmers which is not a good practice.

The farmers mostly finds a lot of problem in hiring a group of people as labours on time for the work which leads to a large damage in the crop or the farmer have to use fertilizers for the time being which results in increment of the cost or the crop damages as well as some rate.

To solve this problem the app fives the facility to field to form a group and upload the availability of the labours from different areas which will reduce the dependency of the farmer on the labours of the village and open more sources that will be easy for the farmers and solve a big problem.

The formation of the group will be also used to sell large quantity products such as maize, wheat, cotton etc which cannot be sold to a individual customer so the app provide an field to form group of farmers and collect a large quantity in tons and sell to a retailer at good price or to industries which will be beneficial to the industry as well as the farmer.

The app provides the option to borrow the equipment's from different farmers and widens the range for the borrowing which will be easy for the farmers and as well the work will be completed in the time.

The farmer having own equipment's must upload the equipment photo and the rent and the location. The needy farmer nearby the wealthy farmer will book the equipment and pay to wealthy farmer accordingly. The app also includes the Hamibhav in putting the price of different goods by the farmers which helps in putting a proper range and benefits both the farmer and the customer.

The Hamibhav inclusion will help to run the app goods price nearby the government prices.

\section{MATERIALS AND METHODS}

The materials used in this project is the GPS of the device to locate the farmer and the customer as well, Google cloud will be used for the authentication of the data of newly registered user, volley will be used for the json parsing or to communicate with the data in the database. Firebase services will be used for the notification services.

REST Api is used to communicate with the database retrieval, sending, deleting the data from the database. The database is connected to the android using the volley library and the jsonParse is done using volley the json object is parse into string format.

The POST method will be used for the connection of the database and the android application. The Api is basically is used to connect the database services to the Android Application

\section{PROPOSED SYSTEM}

After studying the previous system, we found that many issues of the farmers lives were uncovered in those systems. Though the selling of the goods or the marketing of the farming products was made easy but the selling of large quantity products was not taken under consideration all the older system just made the product selling app from farmer to the customer but the a single user cannot take a large quantity of maize 
or wheat at a time from every farmer so to overcome this challenge we implemented group system in the app in which the farmers can form groups in and sell a large quantity to industry and earn a good profit.

We also implement the exchange of tools and vehicles among the farmers on rent and the hiring of labors from nearby areas. The farmers which have the tractor, farming equipment's can upload that on the app along the availability of it and the needy once can book the equipment's on the rents asked by the big farmers. This will lead to gentle exchange of equipment's among themselves.

Our app also provides the facility to hire labor's the must register themselves as labor as an individual or group and the farmer can hire them as per requirement and pay the fees as per mentioned.

The fields in our system are:

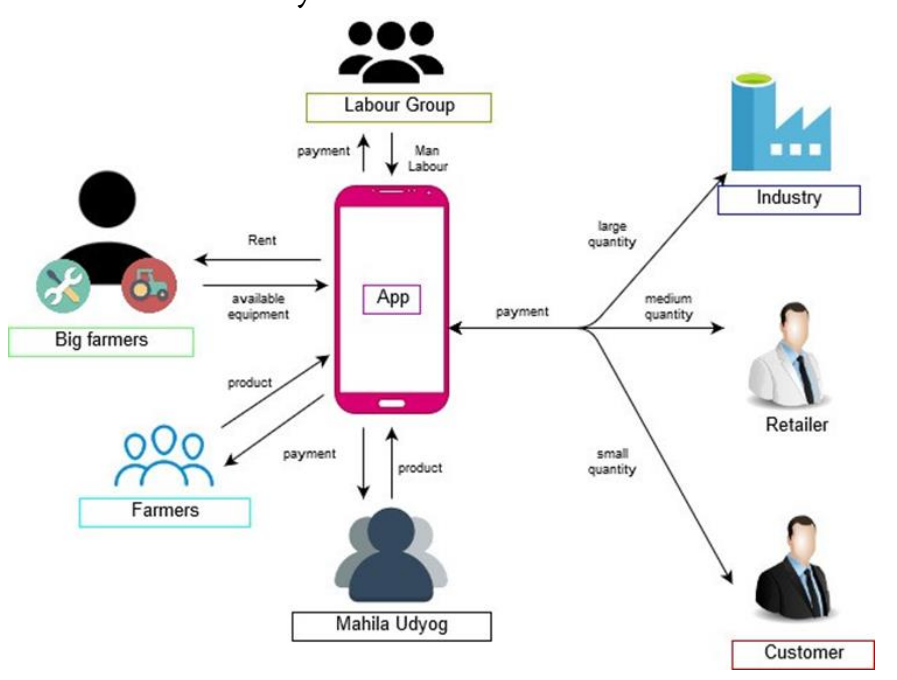

1. Farmers

2. Customer

3. Industry or Retailer

4. Labor

5. Mahila Udyog

6. Rental Vehicles and Tools

7. Payment Method

8. Rating and Review

\section{FARMERS}

The farmers must upload the photos of products and the required details about the product and the location of the farmer will be taken through the gps.

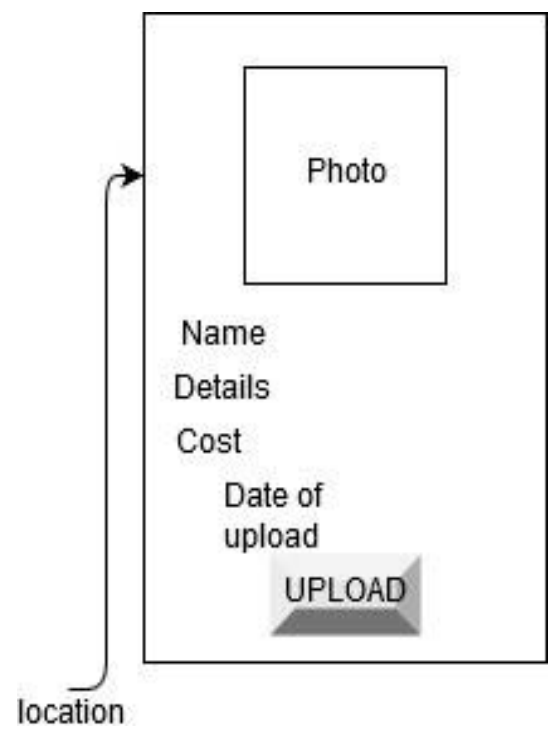

The farmer also can book the tools and vehicles of the big farmers on rent. As well as they have the option to hire labour for work.

\section{CUSTOMER}

The customer has the option to buy the products from the farmer. The customer can buy the product made by the mahila udyog. In feedback the customer must rate the product for the improvement of product and service quality.

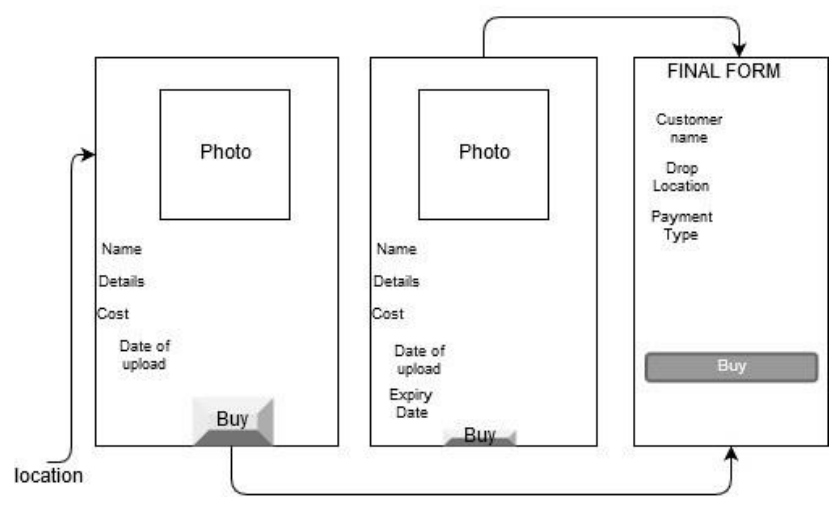

3. INDUSTRY OR RETAILER 
The industrialist can buy the large quantity product from the group of farmers from nearby locations. Like the ginning industry can buy tons of cotton from farmers group from different villages located nearby each other.

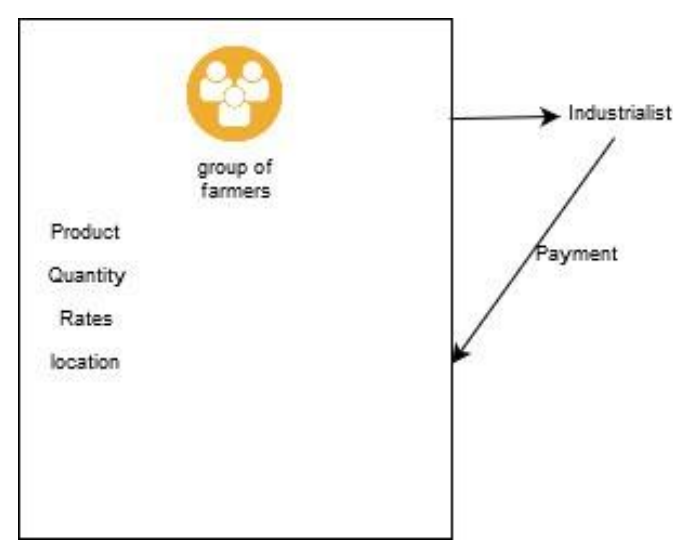

\section{LABOUR}

The labour or the group of labour must register as labour and must put their location and availability on the app. And the labours in group must mention the number of labours in the group.

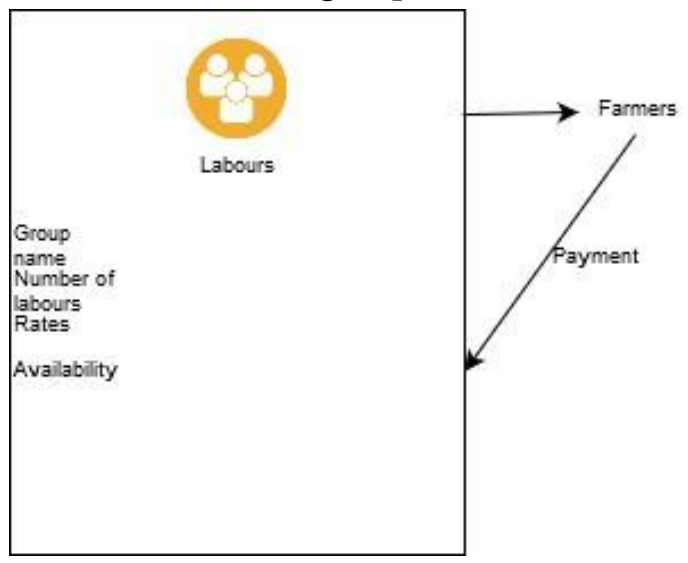

5. MAHILA UDYOG

The mahila's in the village prepare different things like pickle, papad etc. The mahila group first should take the requirement from the customer through the app and prepare the product accordingly and sell it to the customer.
The big farmers who have the tractors and other tools must upload those on the app and must put the location as well so the small farmers nearby can book the equipment's if the requirements are suited.

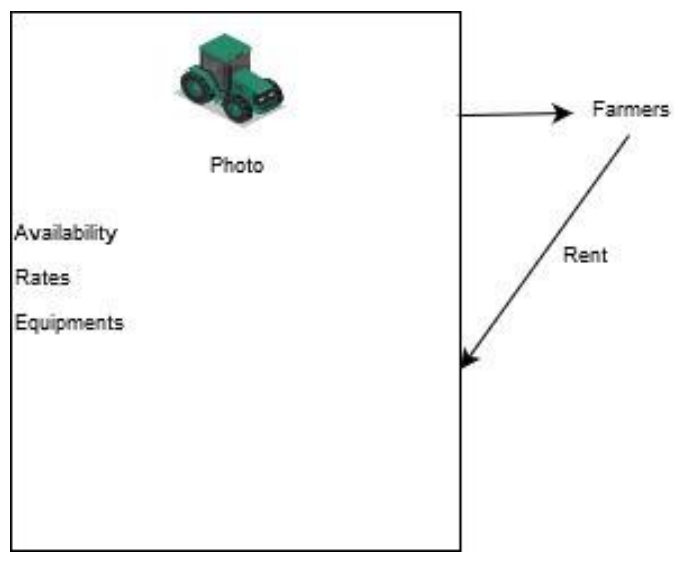

\section{PAYMENT METHOD}

When the customer selects different products from different farmers then the payment is distributed to the farmers accordingly.

And the industrialist buying large quantity from group here the same strategy is used the profit will distributed in different farmers according to the amount of goods in the group.

The payments can be mostly done online and the option of on delivery will be also available.

\section{RATING AND REVIEW}

The customer must give the feedback in the form of rating on different basis on the product to improve the quality of product and the service.

\section{RENTAL TOOLS AND VEHICLES}




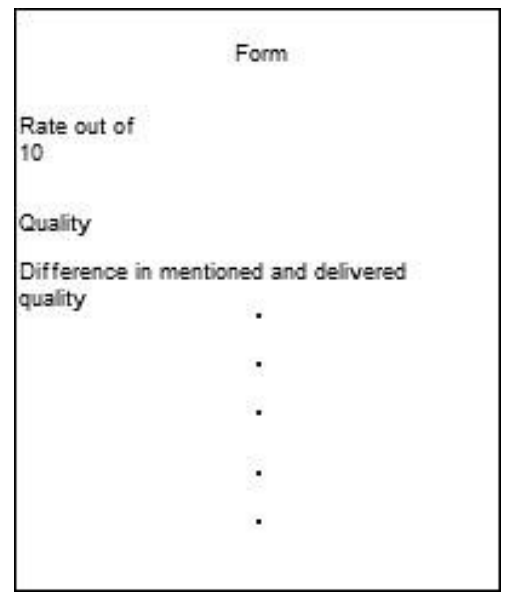

\section{RESULTS AND DISCUSSION}

\section{GOOGLE CLOUD}

The google cloud is used to verify the information on the registration.

\section{REST API}

The api is used to communicate with the database retrieval of data, sending the data to the database, deleting the data from the database. The database is connected to the android using the volley library and the jsonParse is done using volley the json object is parse into string format. An api is program interface that use http request to POST, DELETE, GET and PUT data. The Api is basically is used to connect the database services to the Android Application

\section{GRAPHICAL USER INTERFACE}

The GUI of the application is the way of interacting of the user with the system. The GUI of the application should be user friendly.

The user must register first by filling the registration form in the form the mandatory information should be filled and the user should sign up. The data filled will be stored in the database for the further use.

Once the registration is done the email, phone number will be verified, and the user will be directed in the app. Here the user will have various option like fruit, vegetable, pulses, spices, grains, home made things. If you are customer, then user can opt any of the option and select the required product or else on the first screen all the different kind of products will be available but for user friendly appearance for the specific product buying those options are provided.

Now if the user is farmer, he can opt option of sell the product and the form will appear with various details including photo, name of product, Date of upload, Expiry date, short description of product, Quantity available etc, and click on the upload button the product will be uploaded and can be seen in the specific sector.

Now the customer can select various items from various lists and save all of them in the cart once all the selection is done they can press buy button in cart and select all the final products and the customer details will be asked like drop location, quantity of each product, payment type etc.

Now if the user is a farmer and want to hire a vehicle, farming tool, labour then the option is provided in the drawer box in the rental sector. So, the farmer can just check the list and the availability of the equipment's will be mentioned in the list of products and the location of the farmer uploaded the information so according to convenience the farmer can select the equipment and hire the equipment.

Now here the payment method will be in divisions $30 \%$ of the rent must be given before the use and $70 \%$ after the use.

Once the order is placed the uploader will get notification the order will be picked from the farmer and delivered to the customer. 


\section{CONCLUSION}

The farmer of the country is not aware with the trending technology but though most of the farmers use the android phone. So, the application can be very useful for the farmer and user-friendly behavior can give better experience as well the trade will be gentle, and the life of farmer will be better. The application will fill the gap between the farmer and the customer removing the middleman and profiting the farmer according to the hard work. And the mahila udyog can be extended above the limits. The exchange of equipment's will be gentle rather than going to some farmer and requesting for the tools and vehicles the way of exchange will be better and friendly. The hiring of labor process will be carried with ease. The labor as well as the farmer will be profited no bargaining or waiting for the money will be carried for the labor. Resulting in better business from the farmer point of view and this application will connect the farmer with the world in different manner.

\section{REFERENCES}

[1]. Mrs. Manisha Bhende, Ms. Mohini S. Avatade, Mrs. Suvarna Patil "Digital Market: ECommerce Application For Farmers” 2018 IEEE International Conference on Technological Innovations in ICT For Agriculture and Rural Development

[2]. Abhishek A.G, Bharadwaj M, Bhagyalakshmi L "Agriculture Marketing Using Web and Mobile Based Technologies" Agriculture Marketing Using Web and Mobile Based Technologies

[3]. KiranShinde, Jerrin Andrei, AmeyOke "Web Based Recommendation System for Farmers" march, 2015

[4]. Pravin J. Gupta, Heena R. Mhatre, Aachal P. Chaudhari, Rucha Pathari "SMART LIVESTOCK TRADING"

\section{Cite this article as :}

Shreyas P. Deshmukh, Sufiyan R. Tamboli, Pankaj S. Jadhav, Snehal Barawkar, "E-commerce Agricultural Product Marketing and Rental Vehicle", International Journal of Scientific Research in Science and Technology (IJSRST), Online ISSN : 2395-602X, Print ISSN : 2395-6011, Volume 7 Issue 2, pp. 424-429, March-April 2020. Available at doi : https://doi.org/10.32628/IJSRST207244 Journal URL : http://ijsrst.com/IJSRST207244 